\title{
Role of misfolded tau in the onset and progression of brain toxicity after trauma
}

Elisa R. Zanier ${ }^{*}$, Maria Monica Barzago ${ }^{2}$, Gloria Vegliante $^{1}$, Margherita Romeo ${ }^{2}$, Ilaria Bertani $^{1}$, Carmina Natale ${ }^{1}$, Luca Colnaghi ${ }^{1}$, Laura Colombo ${ }^{2,}$ Luca Russo $^{2}$, Edoardo Micotti ${ }^{1}$, Luana Fioriti $^{1}$, Roberto Chiesa ${ }^{1 *}$, Luisa Diomede ${ }^{2 *}$

${ }^{1}$ Department of Neuroscience and ${ }^{2}$ Department of Molecular Biochemistry and Pharmacology, Istituto di Ricerche Farmacologiche Mario Negri IRCCS, Milan, Italy.

Running title: TBI generated tau is toxic to C. elegans

*Correspondence to:

Luisa Diomede

Department of Molecular Biochemistry and Pharmacology, Istituto di Ricerche

Farmacologiche Mario Negri IRCCS, Via Mario Negri 2, 20156 Milan, Italy.

E-mail: luisa.diomede@marionegri.it

*Correspondence may also be addressed to:

Elisa R. Zanier, E-mail: elisa.zanier@marionegri.it

Roberto Chiesa, E-mail: roberto.chiesa@ marionegri.it 


\begin{abstract}
Traumatic brain injury (TBI) is associated with widespread tau pathology in about one third of patients. We previously found that TBI induces a transmissible tau pathology ( $\left.\operatorname{tau}^{\mathrm{TBI}}\right)$, with late cognitive decline and synaptic dysfunction. To understand whether tau ${ }^{\mathrm{TBI}}$ is a marker of ongoing neurodegeneration or a driver of functional decline, we employed C. elegans. Brain homogenates from chronic TBI mice, or from mice in which tau ${ }^{\mathrm{TBI}}$ had been transmitted by intracerebral inoculation, impaired $C$. elegans motility and neuromuscular synaptic transmission. Brain homogenates from tau P301L transgenic mice, or pre-aggregated recombinant tau, induced a similar toxic response. Protease digestion or pre-incubation of homogenates with anti-tau antibodies abolished toxicity, and TBI brain homogenates from tau knock-out mice had no toxic effect. These results support a vital role of abnormal tau species in chronic neurodegeneration after TBI and set the groundwork for the development of a C. elegans-based platform for screening anti-tau compounds.
\end{abstract}

Keywords: tau, tauopathy, prion, traumatic brain injury, Caenorhabditis elegans. 


\section{INTRODUCTION}

Traumatic brain injury (TBI) is a leading cause of death and disability in young adults worldwide $^{1,2}$. There is a growing acceptance that TBI is an acutely initiated event that results in long-lasting physical, and mental disability. In a sizeable minority TBI may also be a progressive disease, with worsening neuroimaging findings and neurology over months and years, and/or an increased risk of late dementia ${ }^{3,4}$. In the last decade, studies have led to the characterization of the neuropathology in individuals exposed to TBI of varying severity, and across injury survivors, from hours to many decades. These studies have given a complex picture of pathologies, with abnormalities in tau, amyloid beta (A $\beta)$, neuronal loss, axonal degeneration, neuroinflammation and blood-brain barrier disruption - all changes common to wider neurodegenerative diseases ${ }^{5-8}$. The development of hyperphosphorylated tau (p-tau) is a hallmark of Alzheimer's disease, correlating to outcome and late symptomatology ${ }^{9}$, and may be a crucial aspect linking TBI to late dementia. The recent addition of the positron emission tomography ligand flor-taucipir/11C-PBB3 to map tau pathology has provided information about the temporal and spatial characteristics of tau accumulation in the living brain, showing variable increases compared to healthy volunteers years after single or repetitive $\mathrm{TBI}^{10-12}$. However, in the clinical setting it is difficult to disentangle the precise significance of $\mathrm{p}$-tau accumulation from other possible contributors to post-TBI neurodegeneration and/or dementia.

An important recent observation is that experimental TBI in wild-type (WT) mice induces the emergence and accumulation of a p-tau reminiscent of post-TBI tau pathology in humans ${ }^{13,14}$. Studies from our group indicate that this TBI-triggered p-tau pathology ( $\operatorname{tau}^{\mathrm{TBI}}$ ) spreads from the site of injury to remote regions of the brain and can be transmitted to naïve recipient mice by intracerebral inoculation, inducing memory deficits and synaptic alterations ${ }^{14}$. With the observation that $\operatorname{tau}^{\mathrm{TBI}}$ is aggregated and partially resistant to pronase digestion, these results suggest that tau prions are generated in TBI, providing a possible explanation for how a biomechanical insult might trigger self-sustained neurodegeneration. However, it still needs to be established whether tau ${ }^{\mathrm{TBI}}$ has a causal role in driving toxicity, as a primary player in the transition from an acute event to progressive neurodegenerative pathology.

To this aim we turned to the invertebrate Caenorhabditis elegans, which is widely used to investigate pathogenic mechanisms underlying protein-misfolding diseases, including tauopathies ${ }^{15-20}$. We established an integrated approach using brain tissue homogenates from TBI mice and C. elegans which allowed us to test directly whether tau ${ }^{\mathrm{TBI}}$ is the primary toxic 
culprit in post-TBI neurodegeneration. We found that C. elegans motility and neuromuscular synaptic transmission were impaired when the nematodes were administered brain homogenates from chronic but not acute TBI mice, or from mice in which tau ${ }^{\text {TBI }}$ had been transmitted by intracerebral inoculation. There is a therapeutic opportunity to intervene after TBI before significant neurodegeneration takes place, so defining the pathogenic potential of TBI-generated tau proteoforms may have important clinical implications.

\section{RESULTS}

Brain-injured tissue from chronic TBI mice impairs C. elegans motility. We previously found that a single severe TBI induced persistent and evolving tau pathology in WT mice, which progressively spread from the site of injury to ipsi and contralateral brain regions. Ptau deposits were seen adjacent to the site of injury three months post-TBI, and were widespread in the ipsi and contralateral hemispheres at 12 months. Tau ${ }^{\mathrm{TBI}}$ could be transmitted to naïve mice by intracerebral inoculation in a prion-like manner, causing synaptic toxicity and memory deficits ${ }^{14}$. To study tau ${ }^{\mathrm{TBI}}$ toxicity in a more tractable model we used the nematode $C$. elegans, which is susceptible to the toxicity of various amyloidogenic proteins $^{21-24}$.

Synchronized nematodes were incubated at L4 larval stage with brain homogenates $(0.3 \mu \mathrm{g}$ total proteins per worm) from TBI or sham mice euthanized at different times; naïve mice were used as an additional control (Fig. 1a). Locomotor activity and pharyngeal function were scored after 7 days. There was a significant reduction in the frequency of body bends in worms exposed to homogenates from chronic ( 3 and 12 months) but not acute ( $24 \mathrm{~h}$ or $72 \mathrm{~h}$ ) TBI mice (Fig. 1b). Locomotor impairment was induced by brain tissue ipsilateral $\left(\mathrm{TBI}_{\mathrm{ipsi}}\right)$ but not contralateral $\left(\mathrm{TBI}_{\text {contra }}\right)$ to the site of injury collected three months post-TBI, and by both $\mathrm{TBI}_{\mathrm{ipsi}}$ and $\mathrm{TBI}_{\text {contra }}$ tissues at 12 months (Fig. 1b), correlating with the presence of p-tau pathology ${ }^{14}$. The decrease in body bends was first detectable 2 days after treatment, and persisted at 4 and 7 days (Fig. 1c), exacerbating the physiological age-dependent decline in nematode motility (Supplementary Fig. 1a). No effect on pharyngeal pumping was observed at any time (Fig. 1d), indicating a selective neuromuscular defect. There were no changes in body bend frequency or pharyngeal pumping in worms incubated with brain homogenates from naïve or sham mice, compared to untreated controls (Supplementary Fig. 1). 
Tau ${ }^{\text {TBI }}$ mediates toxicity in worms. We used different approaches to investigate whether the abnormal tau that accumulates in TBI mice at chronic stages was responsible for impairing the nematode locomotor function. First, we asked whether a deficit in motility like that induced by TBI homogenates was also seen in worms exposed to brain homogenates from P301L mice, which show robust tau pathology $y^{25}$. Worms were incubated with brain homogenates from nine-month-old P301L mice or age-matched Non-Tg controls, and body bend frequency and pharyngeal activity were scored after seven days. Like in worms treated with TBI tissue, the P301L homogenate significantly impaired body bend frequency but not pharyngeal activity (Fig. 2). The locomotor deficit worsened significantly on doubling the amount of P301L brain homogenate, consistent with a dose-dependent effect (Supplementary Fig. 2).

Next, we asked whether the toxicity of TBI and P301L brains was abolished by treating them with high concentrations of PK, a broad-spectrum serine protease (Fig. 3a, b). Homogenates from $\mathrm{TBI}_{\mathrm{ipsi}}$ (hereafter TBI) were used in all the subsequent experiments. Protein analysis by SDS-PAGE followed by Coomassie staining indicated complete protein digestion (Fig. 3c, d), consistent with tau ${ }^{\mathrm{TBI}}$ being completely degraded by harsh protease digestion. PK completely abolished the ability of brain homogenates from P301L and TBI mice to induce the locomotor defect (Fig. 3e, f and Supplementary videos).

We used several complementary approaches to directly assess the role of tau. First, to see whether anti-tau antibodies could block P301L and TBI homogenate toxicities, we treated the nematodes with P301L or TBI brain homogenates preincubated with or without the T46 antibody, which recognizes the C-terminal region of both human and mouse tau, or the SP70 antibody recognizing the N-terminal domain of human but not mouse tau (Fig. 4). Incubation with native but not heat-inactivated T46 antibody prevented the motility defect caused by the P301L and TBI brain homogenates (Fig. 4c, e and Supplementary Fig. 3). P301L toxicity was also abrogated by the human tau-specific SP70 antibody (Fig. 4d). These results point to direct involvement of tau in toxicity.

Next, we tested the toxicity of chronic TBI brain homogenates from tau KO mice. WT and tau KO mice were subjected to TBI or sham injury and euthanized after 4 months. There were no differences between WT and tau KO mice in TBI-induced sensorimotor deficits rated with the neuroscore and SNAP tests at 1 and 4 months (Fig. 5a, b) or in contusion volume assessed by T2w-MRI at 4 months (Fig. 5c, d). C. elegans treated with TBI homogenates from WT mice had significantly fewer body bends than those treated with WT sham homogenates, while homogenates from TBI tau KO mice had no effect (Fig. 5e, f). 
Finally, we investigated whether exposing the nematodes to purified recombinant tau was sufficient to induce the deficit in body bends. Recombinant human 2N4R tau, either WT (TauwT) or P301L (Taup301L), was given to worms in the form of soluble monomers or insoluble aggregates obtained by incubating the proteins with heparin for $24 \mathrm{~h}$ (Fig. 6a). There were no changes in motility in worms incubated with monomeric TauwT or Taup301L, whereas the aggregated proteins significantly reduced body bends (Fig. 6b), but not pharyngeal activity (data not shown). The toxicity caused by aggregated tau was similar to that induced by P301L or TBI brain homogenates. These findings indicate that the toxic effect of tau on the $C$. elegans neuromuscular apparatus is related to its state of aggregation, independently from its phosphorylation, since the recombinant protein is not phosphorylated and further support a role for misfolded tau in the locomotor deficit caused by TBI brain homogenates.

The locomotor impairment is due to neurotransmission failure. We investigated whether the locomotor dysfunction in nematodes treated with TBI or P301L brain homogenates could be ascribed to an impairment of synaptic transmission by analyzing the sensitivity to the paralyzing effect of aldicarb or levamisole. These pharmacological assays are commonly employed in $C$. elegans to depict the contribution of pre- and post-synaptic dysfunction to motility defects ${ }^{26}$. Aldicarb, an acetylcholinesterase inhibitor, causes the spastic paralysis of worms due to excessive acetylcholine build-up at the neuromuscular junction ${ }^{26}$. The speed of onset of paralysis depends on the acetylcholine released from the pre-synapse and the postsynapse competency in translating the cholinergic signal into a muscle contraction. Levamisole, a nicotinic acetylcholine receptor agonist, causes spastic paralysis by binding to acetylcholine receptors at post-synaptic sites on the neuromuscular junction ${ }^{26}$. Therefore, aldicarb gives information on the presence of both pre- and post-synaptic dysfunctions while levamisole indicates a post-synaptic defect.

The sensitivity to the paralyzing effect of aldicarb or levamisole was evaluated in nematodes treated with TBI, sham, P301L or Non-Tg homogenates or an equal volume of $10 \mathrm{mM}$ PBS, pH 7.4 (vehicle).

Sensitivity to aldicarb was significantly greater in TBI- than in sham-treated nematodes and sensitivity to levamisole was reduced, indicating that both pre- and post-synaptic defects are responsible for the motility impairment (Fig. 7a, b). Results were similar in nematodes treated with brain homogenates from P301L mice (Fig. 7c, d). 
Brain homogenates of mice replicating tau ${ }^{\mathrm{TBI}}$ prions are toxic to $C$. elegans. We previously found that the hippocampus and thalamus are the two brain regions with the most prominent tau pathology in mice in which tau ${ }^{\mathrm{TBI}}$ was transmitted by intracerebral inoculation 14. We asked whether brain homogenates from these two brain regions were toxic to nematodes. Homogenates were administered to worms and their locomotor activity was rated seven days later. There was a significant reduction in body bend frequency in worms treated with tau ${ }^{\text {TBI }}$ - but not sham-inoculated homogenates (Fig. 8). The motility defect caused by brain homogenates from tau ${ }^{\mathrm{TBI}}$-inoculated mice was comparable to that of worms treated with TBI homogenates (Fig. 1) indicating that the toxic properties of TBI-generated tau remained unaltered upon transmission and self-propagation in naïve mice.

\section{DISCUSSION}

This study shows that brain-injured tissue from chronic TBI mice impairs motility and synaptic transmission in C. elegans, and this is directly attributable to the abnormal form of tau that accumulates over time after TBI. These data indicate a pivotal role of abnormal tau conformers in chronic neurodegeneration after TBI.

C. elegans is widely used to investigate the cell-autonomous and non-cell-autonomous mechanisms underlying the pathogenesis of human disease ${ }^{20}$. Its genes and pathways have a high degree of homology with those of vertebrates ${ }^{15,27}$ and its small size, short reproductive life cycle and lifespan allow to give large volumes of data in a short time ${ }^{15}$. In the context of protein misfolding neurodegenerative diseases and systemic amyloidosis, C. elegans has been used as a biosensor of toxic amyloidogenic proteins, as shown by our previous studies employing synthetic A $\beta, \mathrm{HIV}-1$ matrix protein p17 peptides, amyloidogenic immunoglobulin light chains purified from patients' biological fluids and recombinant gelsolin domains ${ }^{21-24,28}$. This simple system has helped elucidate proteotoxic mechanisms and pave the way for novel therapeutic approaches ${ }^{22,29}$.

In the present study we exploited the biosensor properties of $C$. elegans to test the hypothesis that abnormal tau conformers play a causal role in driving toxicity in TBI. Chronic (3 and 12 months) but not acute ( 24 and $72 \mathrm{~h}$ ) TBI tissue was toxic to nematodes, inducing a selective defect in locomotor activity. This indicates that toxicity is due to pathological changes occurring in the injured brain at chronic stages rather than to acute events, such as excitotoxicity, oxidative stress or acute inflammation. While at three months post-TBI only the ipsilateral brain homogenate was toxic, at 12 months both the ipsi and contralateral 
tissues induced the locomotor defect. This correlated with the progressive spread of tau pathology from the site of contusion to the ipsi- and contra-lateral brain hemispheres ${ }^{13,14}$.

This contention was further supported by the observation that brain homogenates from P301L mice, which develop genetically determined p-tau pathology with age, had similar deleterious effects on nematode neuromuscular function. The absence of toxicity in worms fed brain homogenates from sham or Non-Tg mice indicated the specificity of the effect and suggested that age-related brain changes other than p-tau accumulation had no role. The observation that the TBI and P301L brain homogenate toxicities were abolished by anti-tau antibodies, that brain homogenates from TBI tau KO mice were not toxic, and that recombinant tau was toxic to the worms, provided strong evidence of a direct role of tau. While in P301L mice proteinopathies other than tau have not been reported ${ }^{25}$, TBI favors misfolding of other proteins, accelerating $\mathrm{A} \beta$ and TDP-43 deposition ${ }^{5,30}$. A $\beta$ administered to $C$. elegans is associated with transient pharyngeal impairment, but no motility deficits ${ }^{21,28}$, and in worms fed TBI tissue no pharyngeal impairment was observed. This confirms the primary role of tau in TBI-related toxicity and suggests that $\mathrm{A} \beta$ has a negligible effect if any.

C. elegans neuromuscular integrity and synaptic function deteriorate with age, contributing to the motility decline ${ }^{31}$. The defect in motility caused by TBI and P301L brain homogenates, however, was not due to hastened aging, since the lifespan of the nematodes was not affected (Supplementary Fig. 4). In aldicarb and levamisole sensitivity tests, the locomotor impairment was associated more with defective synaptic transmission, pointing to a synaptotoxic effect of tau. Transgenic $C$. elegans expressing human WT tau 2N4R in neurons accumulate insoluble forms of p-tau and, like worms fed TBI and P301L brain homogenates, have no impairment in pharyngeal function but develop locomotor and pre- and post-synaptic defects $^{32}$. This suggests that the proteotoxic mechanisms of the neuromuscolar dysfunction induced by transgenically expressed and exogenously administered tau involve common molecular targets.

There is growing interest in the role of tau in post-TBI neurodegeneration, and the idea that targeting pathological tau may point to a therapeutic opportunity in TBI is growing ${ }^{13,33-35}$. The $C$. elegans model of tau ${ }^{\mathrm{TBI}}$ toxicity described here could be employed to rapidly screen TBI conditions involving the generation of potentially toxic tau species in both experimental and human TBI, to investigate the mechanisms underpinning chronic neurodegeneration in TBI, and to develop a high-throughput experimental platform to screen for pharmacological agents that interfere with TBI-associated tau toxicity. 


\section{METHODS}

Mice. Male C57BL/6J mice, referred to as WT mice, were purchased from Envigo (Holland).

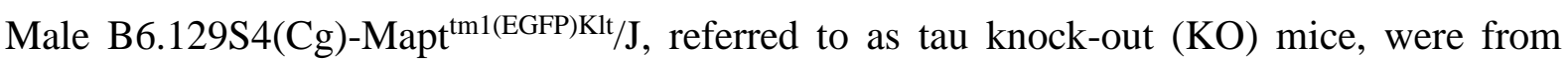
Jackson Laboratory (\#029219, USA) ${ }^{36}$. Male JNPL3 mice expressing 0N4R human tau with the P301L mutation (P301L) were obtained from Taconic Biosciences (New York, USA) (Tau- Model 2508). Controls were non-transgenic (Non-Tg) male mice with the same mixed C57BL/6, DBA/2, SW genetic background as P301L mice. Mice were housed in a specific pathogen-free animal room at a constant temperature of $21 \pm 1{ }^{\circ} \mathrm{C}$, humidity $60 \pm 5 \%$, with a $12 \mathrm{~h}$ light/dark cycle, and ad libitum access to food and water.

Procedures involving animals and their care were conducted in conformity with the institutional guidelines at the Istituto di Ricerche Farmacologiche Mario Negri IRCCS in compliance with national (D.lgs 26/2014; Authorization n. 19/2008-A issued March 6, 2008 by Ministry of Health) and international laws and policies (EEC Council Directive 2010/63/UE; the NIH Guide for the Care and Use of Laboratory Animals, 2011 edition). They were reviewed and approved by the Mario Negri Institute Animal Care and Use Committee that includes ad hoc members for ethical issues, and by the Italian Ministry of Health (Decreto no. D/07/2013-B and 301/2017-PR). Animal facilities meet international standards and are regularly checked by a certified veterinarian who is responsible for health monitoring, animal welfare supervision, experimental protocols and review of procedures.

Mouse model of TBI. The controlled cortical impact brain injury mouse model used in this study replicates both the mechanical forces and the main secondary injury processes observed in severe TBI patients with brain contusion and gives clinically-relevant behavioral and histopathological outcomes ${ }^{14,37}$. WT and tau KO mice were anesthetized by isoflurane inhalation (induction 3\%; maintenance $1.5 \%$ ) in an $\mathrm{N}_{2} \mathrm{O} / \mathrm{O}_{2}(70 \% / 30 \%)$ mixture and placed in a stereotaxic frame. Rectal temperature was maintained at $37^{\circ} \mathrm{C}$. Mice were then subjected to craniectomy followed by induction of controlled cortical impact brain injury as previously described ${ }^{38}$. Briefly, the injury was induced using a 3-mm rigid impactor driven by a pneumatic piston rigidly mounted at an angle of $20^{\circ}$ from the vertical plane and applied to the exposed dura mater, between bregma and lambda, over the left parietotemporal cortex (antero-posteriority: $-2.5 \mathrm{~mm}$, laterality: $-2.5 \mathrm{~mm}$ ), at an impactor velocity of $5 \mathrm{~m} / \mathrm{s}$ and deformation depth $1 \mathrm{~mm}$, resulting in a severe level of injury ${ }^{39}$. The craniotomy was then covered with a cranioplasty and the scalp sutured. Sham mice received identical anesthesia 
and surgery without brain injury. Mice were allocated to surgery by a list randomizer (http://www.random.org/list). All behavioral evaluations and magnetic resonance imaging (MRI) analysis were done blinded to injury status and genetic background.

Sensorimotor function. TBI-induced sensorimotor deficits were assessed on WT and tau KO mice by the Neuroscore and Simple Neuroassessment of Asymmetric Impairment (SNAP) tests 4 months post-TBI. Neuroscore. Mice are scored from 4 (normal) to 0 (severely impaired) for each of the following indices: 1) forelimb function while walking on the grid and flexion function response when suspended by the tail; 2) hindlimb function while walking on the grid and extension function when suspended by the tail; and 3) resistance to lateral right and left pulsion. The maximum score per mouse is $12^{38,40}$. SNAP. The test evaluates eight neurological parameters including vision, proprioception, motor strength and posture. Score ranges from 0 (normal) to 5 (severely impaired) for each test. The scores from each of the eight tests are summed to give the total SNAP score. A neurologically intact animal would be expected to have a SNAP score of 0 . The higher the score the more the asymmetric deficits $^{41}$.

Magnetic resonance imaging. Imaging studies were done four months after TBI. Images were acquired on a 7T Bruker Biospec (Ettlingen, Germany) running ParaVision 6.01, equipped with a quadrature cryogenic surface coil as transmitter and receiver. Mice were anesthetized (induction $3-4 \%$, maintenance $1.5-2 \%$ in an air/ $\mathrm{O}_{2}-70 \% / 30 \%$ mixture) and body temperature was maintained at $37^{\circ} \mathrm{C}$. Acquisitions: coronal, 2D, T2-weighted RARE sequences with FOV $1.5 \times 1.5 \mathrm{~cm}$, matrix $150 \times 150$, 37 slices $300 \mu \mathrm{m}$ thick, repetition time TR $5500 \mathrm{~ms}$, echo time $\mathrm{E}=66 \mathrm{~ms}$, RARE factor of 8 and number of averages $\mathrm{N}=12$. Contusion volume was computed using the ITK-SNAP software.

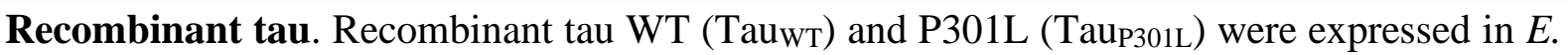
coli and purified by exchange chromatography followed by size-exclusion chromatography. The purification protocol was adapted from Rossi et $a .^{42}$. Aggregation was induced by incubating the proteins with heparin (Mr 6000-20000, Selleckchem), in a tau:heparin ratio of 4:1 (w/w) in $10 \mathrm{mM}$ phosphate buffered saline (PBS), $\mathrm{pH} 7.4$, for $24 \mathrm{~h}$ at $37^{\circ} \mathrm{C}$ with shacking. To assess aggregation, the samples were examined in a detergent insolubility assay adapted from Drisaldi et al. ${ }^{43}$ and the proteins in the supernatant and pellet were analyzed by Western blot using the anti-tau rabbit polyclonal antibody DAKO (Agilent Technologies Italy SpA, 
Milan, Italy) (1:10000 dilution). Anti-rabbit IgG peroxidase conjugate (1:20000, Sigma) was used as secondary antibody.

Proteinase-K digestion. Brain homogenates (30 $\mu \mathrm{g}$ proteins) from the ipsi pericontusional area of 3 months post-TBI and sham-injured mice, Non-Tg and P301L were incubated for $1 \mathrm{~h}$ at $37^{\circ} \mathrm{C}$ with $10 \mu \mathrm{g} / \mathrm{mL}$ proteinase-K (PK) or the same volume of water. After incubation, 2 $\mu \mathrm{g}$ of digested proteins were suspended in $4 \mathrm{X}$ SDS (sodium dodecyl sulfate) loading buffer, boiled for 5 min and analyzed in 10\% SDS-PAGE, followed by Comassie Blue R250 staining for $30 \mathrm{~min}$.

C. elegans studies. Bristol N2 nematodes were obtained from the Caenorhabditis elegans Genetic Center (CGC, University of Minnesota, Minneapolis, MN, USA) and propagated at $20^{\circ} \mathrm{C}$ on solid Nematode Growth Medium (NGM) seeded with E. coli OP50 (CGC) for food. We used the bleaching technique to prepare age-synchronized animals ${ }^{44}$. C. elegans at the first larval stage were then transferred to fresh NGM plates and grown at $20^{\circ} \mathrm{C}$.

At L3-L4 larval stage nematodes were collected with M9 buffer, centrifuged, and washed twice with $10 \mathrm{mM}$ PBS, $\mathrm{pH} 7.4$, to eliminate bacteria. Worms were incubated for $2 \mathrm{~h}$ at room temperature with orbital shaking, in the absence of E. coli, with homogenates from ipsi or contralateral (contra) areas from WT or tau KO TBI mice, the equivalent area of either WT or tau KO sham mice, or brain homogenates from Non-Tg and P301L mice (30-60 $\mu \mathrm{g}$ protein/100 worms $/ 100 \mu \mathrm{L}$ in $10 \mathrm{mM}$ PBS, $\mathrm{pH}$ 7.4). Tauwt or Taup301L (30 $\mu \mathrm{g}$ protein/100 worms $/ 100 \mu \mathrm{L}$ ) were administered to worms in $10 \mathrm{mM}$ PBS, $\mathrm{pH}$ 7.4. Worms incubated with brain homogenates of naïve mice $(30 \mu \mathrm{g}$ protein/100 worms/100 $\mu \mathrm{L})$ or $10 \mathrm{mM} \mathrm{PBS,} \mathrm{pH} 7.4$ (100 worms $/ 100 \mu \mathrm{L})$ were used as negative controls. Worms were then plated onto NGM plates seeded with OP50 E. coli, grown at $20^{\circ} \mathrm{C}$ and transferred every day to new NGM plates seeded with $E$. coli to avoid overlapping generations.

The locomotor activity and the pharyngeal function of nematodes were scored before (time 0 ) and 2, 4, and 7 days after the treatment ${ }^{22,32}$. To measure the locomotor activity, worms were picked up, transferred into a well of a 96-well ELISA plate containing $100 \mu \mathrm{L}$ of $\mathrm{ddH}_{2} \mathrm{O}$ and their motility was evaluated by counting the number of left-right movements in 1 minute (body bends/min). The pharyngeal pumping rate was measured by counting the number of times the terminal bulb of the pharynx contracted in 1minute (pumps/min). 
Brain homogenates (30 $\mu \mathrm{g}$ proteins) from the pericontusional area of 12 months post-TBI and sham-injured mice, Non-Tg and P301L were incubated for $1 \mathrm{~h}$ at $37^{\circ} \mathrm{C}$ with $10 \mu \mathrm{g} / \mathrm{mL}$ PK or the same volume of water. The homogenates were then given to $C$. elegans $(30 \mu \mathrm{g}$ proteins $/ 100$ worms $/ 100 \mu \mathrm{L}$ ) as described above. Control worms were treated with $100 \mu \mathrm{L}$ of water $\pm 10 \mu \mathrm{g} / \mathrm{mL}$ PK. Worms were then plated onto NGM plates seeded with OP50 E. coli, grown at $20^{\circ} \mathrm{C}$ and transferred every day for six days to new NGM plates seeded with E. coli. Locomotor activity was rated on the seventh day after treatment.

In some experiments, $\mathrm{N} 2$ nematodes were fed for $2 \mathrm{~h}$ with the different brain homogenates (30 $\mu \mathrm{g}$ proteins/100 worms $/ 100 \mu \mathrm{L}$ ) previously incubated or not for $30 \mathrm{~min}$ at room temperature with 5-50 ng/ $\mu \mathrm{L}$ anti-mouse tau monoclonal antibody T46 (Thermo Scientific) or anti-human tau monoclonal antibody SP70 (Rockland, Limerick, PA, USA). Antibodies alone were employed as controls. Worms were also treated in the same conditions with brain homogenates incubated for $30 \mathrm{~min}$ at room temperature with $10 \mathrm{ng} / \mu \mathrm{L}$ of T46 antibody inactivated by incubation at $100^{\circ} \mathrm{C}$ for $10 \mathrm{~min}$ (inactivated T46) or the corresponding volume of $10 \mathrm{mM}$ PBS, pH 7.4. Worms were then plated onto NGM plates seeded with OP50 E. coli, grown at $20^{\circ} \mathrm{C}$ and transferred every day for six days to new NGM plates seeded with E. coli. Locomotor activity was rated on the seventh day. All behavioral evaluations were done blinded.

Sensitivity to aldicarb and levamisole. The sensitivity of worms to aldicarb and levamisole was evaluated four days after treatment with brain homogenates. Nematodes (50 worms/plate) on NGM agar plates with OP50 E. coli, were treated with $0.5 \mathrm{mM}$ aldicarb (Sigma Aldrich) or $1 \mathrm{mM}$ levamisole (Sigma Aldrich). The worms were prodded on the nose after $15 \mathrm{~min}$ and 30-min intervals for the next $4 \mathrm{~h}$ to determine when paralysis was complete $^{26}$.

Lifespan. For lifespan experiments, L4 worms were fed for $2 \mathrm{~h}$ with the different brain homogenates, described above. Nematodes were then plated onto NGM plates seeded with OP50 E. coli and kept at $20^{\circ} \mathrm{C}$. To avoid overlapping generations, live worms were transferred daily to fresh NGM plates seeded with OP50 E. coli without fluorodeoxyuridine until they were all dead. Nematodes were scored as dead when there was no touch-provoked movement. The first day of adulthood is day 1 in survival curves. 
Statistical analysis. The data were analyzed using GraphPad Prism 8.0 software (CA, USA) by Student's t-test, one-way or two-way ANOVA and Bonferroni's or Tukey's post hoc test. The median survivals were determined using the same software. A p value $<0.05$ was considered significant.

\section{Data availability}

The data that support the findings of this study are available from the corresponding author, upon reasonable request.

\section{ACKNOWLEDGEMENTS}

This work was supported by Fondazione Regionale per la Ricerca Biomedica (Care4NeuroRare CP_20/2018) to LD; the Alzheimer's Association (AARG-17-532633 to ERZ and RC, AARG-17-505136 to LF; Fondazione Telethon (Telethon Career Award TCP15011) to LF. LC is the recipient of the BrightFocus award (A2019296F) and the Fondo di Beneficenza - Gruppo Intesa Sanpaolo. C. elegans and OP50 E. coli were provided by the GCG, which is funded by NIH Office Research Infrastructure Programs (P40 OD010440). The authors would like to thank Prof David K Menon for numerous useful discussions.

\section{CONTRIBUTIONS}

Conceptualization: E.R.Z., R.C., and L.D.; Design and performance of experiments: M.M.B., G.V., M.R., and L.C.; Additional experimental work: I.B., C.N., L.COLO., L.R., and E.M.; Writing: E.R.Z., R.C., and L.D.; Data discussion and analysis: E.R.Z., R.C., L.D. and L.F.; Funding L.D., E.R.Z., R.C. and L.C.; Supervision: E.R.Z., R.C., and L.D.

\section{COMPETING INTERESTS}

The authors declare no competing interests. 


\section{REFERENCES}

1. McMillan, T. M., Teasdale, G. M., Weir, C. J. \& Stewart, E. Death after head injury: the 13 year outcome of a case control study. Journal of Neurology, Neurosurgery \& Psychiatry 82, 931-935 (2011).

2. Maas, A. I. R. et al. Traumatic brain injury: integrated approaches to improve prevention, clinical care, and research. The Lancet Neurology 16, 987-1048 (2017).

3. Fann, J. et al. Long-term risk of dementia among people with traumatic brain injury in Denmark: a population-based observational cohort study. The Lancet Psychiatry 5, (2018).

4. Nordström, A. \& Nordström, P. Traumatic brain injury and the risk of dementia diagnosis: A nationwide cohort study. PLoS Med 15, e1002496 (2018).

5. Smith, D. H., Johnson, V. E. \& Stewart, W. Chronic neuropathologies of single and repetitive TBI: substrates of dementia? Nat Rev Neurol 9, 211-221 (2013).

6. McKee, A. C. et al. The spectrum of disease in chronic traumatic encephalopathy. Brain 136, 43-64 (2013).

7. McKee, A. C., Daneshvar, D. H., Alvarez, V. E. \& Stein, T. D. The neuropathology of sport. Acta Neuropathol. 127, 29-51 (2014).

8. Hay, J., Johnson, V. E., Smith, D. H. \& Stewart, W. Chronic Traumatic Encephalopathy: The Neuropathological Legacy of Traumatic Brain Injury. Annu Rev Pathol 11, 21-45 (2016).

9. Braak, H. \& Braak, E. Staging of Alzheimer's disease-related neurofibrillary changes. Neurobiol. Aging 16, 271-278; discussion 278-284 (1995).

10. Gorgoraptis, N. et al. In vivo detection of cerebral tau pathology in long-term survivors of traumatic brain injury. Science Translational Medicine 11, (2019).

11. Stern, R. A. et al. Tau Positron-Emission Tomography in Former National Football League Players. N Engl J Med 380, 1716-1725 (2019).

12. Takahata, K. et al. PET-detectable tau pathology correlates with long-term neuropsychiatric outcomes in patients with traumatic brain injury. Brain : a journal of neurology 142, 3265-3279 (2019).

13. Kondo, A. et al. Antibody against early driver of neurodegeneration cis P-tau blocks brain injury and tauopathy. Nature 523, 431-436 (2015).

14. Zanier, E. R. et al. Induction of a transmissible tau pathology by traumatic brain injury. Brain (2018) doi:10.1093/brain/awy193. 
15. Culetto, E. \& Sattelle, D. B. A role for Caenorhabditis elegans in understanding the function and interactions of human disease genes. Hum Mol Genet 9, 869-877 (2000).

16. Kraemer, B. C. et al. Neurodegeneration and defective neurotransmission in a Caenorhabditis elegans model of tauopathy. Proc. Natl. Acad. Sci. U.S.A. 100, 99809985 (2003).

17. Brandt, R., Gergou, A., Wacker, I., Fath, T. \& Hutter, H. A Caenorhabditis elegans model of tau hyperphosphorylation: Induction of developmental defects by transgenic overexpression of Alzheimer's disease-like modified tau. Neurobiology of aging 30, 2233 (2007).

18. Kraemer, B. \& Schellenberg, G. D. Using Caenorhabditis elegans models of neurodegenerative disease to identify neuroprotective strategies. Int. Rev. Neurobiol. 77, 219-246 (2007).

19. Fatouros, C. et al. Inhibition of tau aggregation in a novel Caenorhabditis elegans model of tauopathy mitigates proteotoxicity. Hum Mol Genet 21, 3587-3603 (2012).

20. Nussbaum-Krammer, C. I. \& Morimoto, R. I. Caenorhabditis elegans as a model system for studying non-cell-autonomous mechanisms in protein-misfolding diseases. Dis Model Mech 7, 31-39 (2014).

21. Stravalaci, M. et al. Specific Recognition of Biologically Active Amyloid- $\beta$ Oligomers by a New Surface Plasmon Resonance-based Immunoassay and an in Vivo Assay in Caenorhabditis elegans. J Biol Chem 287, 27796-27805 (2012).

22. Diomede, L. et al. A Caenorhabditis elegans-based assay recognizes immunoglobulin light chains causing heart amyloidosis. Blood 123, 3543-3552 (2014).

23. Zeinolabediny, Y. et al. HIV-1 matrix protein p17 misfolding forms toxic amyloidogenic assemblies that induce neurocognitive disorders. Sci Rep 7, 10313 (2017).

24. Giorgino, T. et al. Nanobody interaction unveils structure, dynamics and proteotoxicity of the Finnish-type amyloidogenic gelsolin variant. Biochimica et Biophysica Acta (BBA) - Molecular Basis of Disease 1865, 648-660 (2019).

25. Lewis, J. et al. Neurofibrillary tangles, amyotrophy and progressive motor disturbance in mice expressing mutant (P301L) tau protein. Nat Genet 25, 402-405 (2000).

26. Mahoney, T. R., Luo, S. \& Nonet, M. L. Analysis of synaptic transmission in Caenorhabditis elegans using an aldicarb-sensitivity assay. Nat Protoc 1, 1772-1777 (2006).

27. Siepel, A. et al. Evolutionarily conserved elements in vertebrate, insect, worm, and yeast genomes. Genome Res. 15, 1034-1050 (2005). 
28. Stravalaci, M. et al. The Anti-Prion Antibody 15B3 Detects Toxic Amyloid- $\beta$ Oligomers. Journal of Alzheimer"s disease : JAD 53, 1485-1497 (2016).

29. Wechalekar, A. D. \& Whelan, C. Encouraging impact of doxycycline on early mortality in cardiac light chain (AL) amyloidosis. Blood Cancer Journal 7, e546-e546 (2017).

30. Tan, X. L. et al. Transactive Response DNA-Binding Protein 43 Abnormalities after Traumatic Brain Injury. J. Neurotrauma (2018) doi:10.1089/neu.2017.5491.

31. Mulcahy, B., Holden-Dye, L. \& O’Connor, V. Pharmacological assays reveal age-related changes in synaptic transmission at the Caenorhabditis elegans neuromuscular junction that are modified by reduced insulin signalling. Journal of Experimental Biology 216, 492-501 (2013).

32. Morelli, F. et al. V363I and V363A mutated tau affect aggregation and neuronal dysfunction differently in C. elegans. Neurobiology of Disease 117, (2018).

33. Lu, K. P. et al. Potential of the Antibody Against cis-Phosphorylated Tau in the Early Diagnosis, Treatment, and Prevention of Alzheimer Disease and Brain Injury. JAMA Neurol 73, 1356-1362 (2016).

34. Katsumoto, A., Takeuchi, H. \& Tanaka, F. Tau Pathology in Chronic Traumatic Encephalopathy and Alzheimer's Disease: Similarities and Differences. Front Neurol 10, (2019).

35. Rubenstein, R. et al. Novel Mouse Tauopathy Model for Repetitive Mild Traumatic Brain Injury: Evaluation of Long-Term Effects on Cognition and Biomarker Levels After Therapeutic Inhibition of Tau Phosphorylation. Front Neurol 10, (2019).

36. van Hummel, A. et al. No Overt Deficits in Aged Tau-Deficient C57B1/6.Mapttm1(EGFP)Kit GFP Knockin Mice. PLoS ONE 11, e0163236 (2016).

37. Pischiutta, F. et al. Single severe traumatic brain injury produces progressive pathology with ongoing contralateral white matter damage one year after injury. Exp. Neurol. 300, 167-178 (2018).

38. Zanier, E. R. et al. Fractalkine Receptor Deficiency Is Associated with Early Protection but Late Worsening of Outcome following Brain Trauma in Mice. J Neurotrauma 33, 1060-1072 (2016).

39. Smith, D. H. et al. A Model of Parasagittal Controlled Cortical Impact in the Mouse: Cognitive and Histopathologic Effects. Journal of Neurotrauma 12, 169-178 (1995).

40. Zanier, E. R. et al. Bone marrow mesenchymal stromal cells drive protective M2 microglia polarization after brain trauma. Neurotherapeutics 11, 679-695 (2014). 
41. Shelton, S. B. et al. A simple, efficient tool for assessment of mice after unilateral cortex injury. J. Neurosci. Methods 168, 431-442 (2008).

42. Rossi, G. et al. Different mutations at V363 MAPT codon are associated with atypical clinical phenotypes and show unusual structural and functional features. Neurobiology of aging 35, 408-417 (2014).

43. Drisaldi, B. et al. SUMOylation Is an Inhibitory Constraint that Regulates the Prion-like Aggregation and Activity of CPEB3. Cell Reports 11, 1694-1702 (2015).

44. Porta-de-la-Riva, M., Fontrodona, L., Villanueva, A. \& Cerón, J. Basic Caenorhabditis elegans Methods: Synchronization and Observation. JoVE 4019 (2012) doi:10.3791/4019. 
a
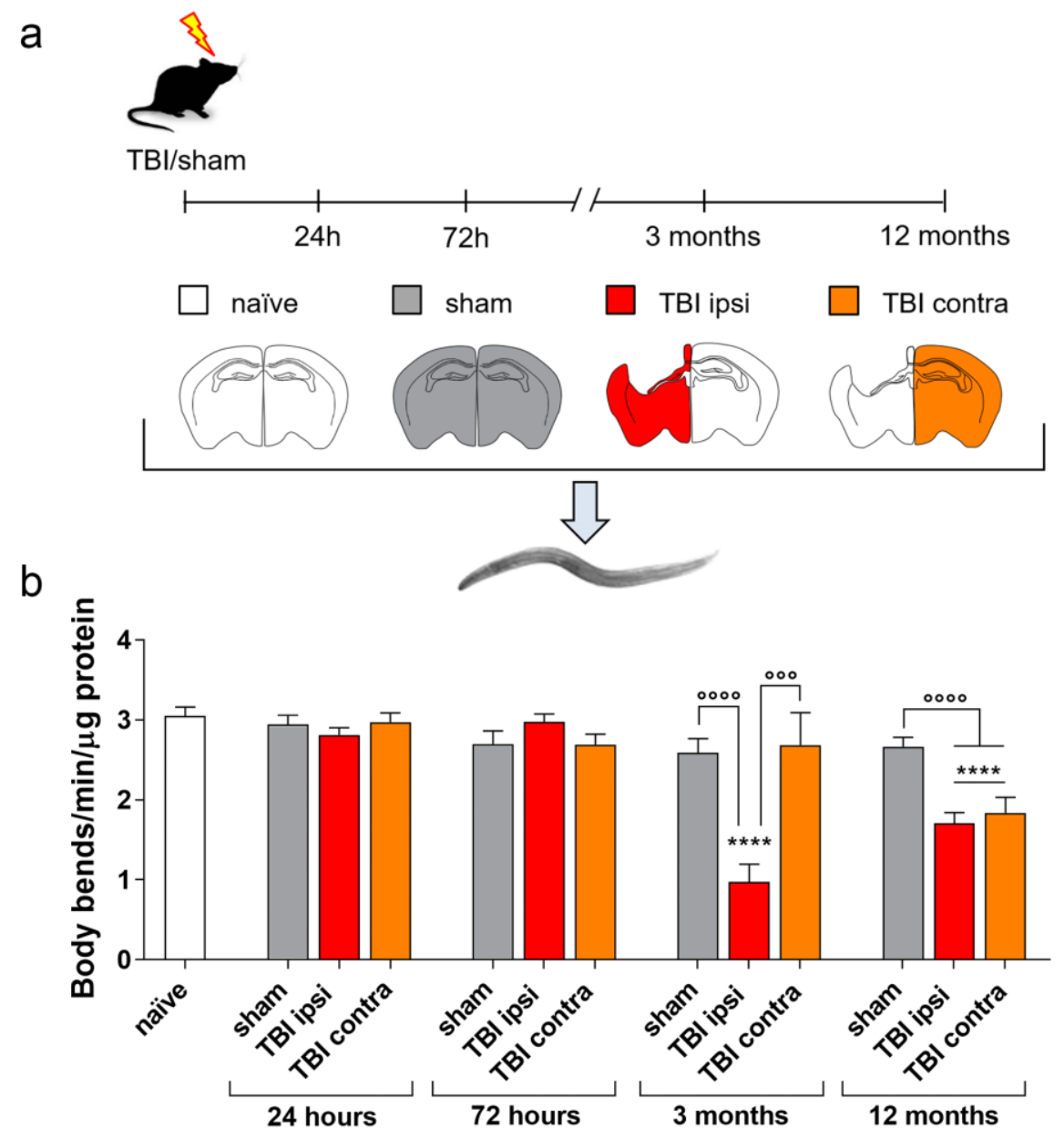

C

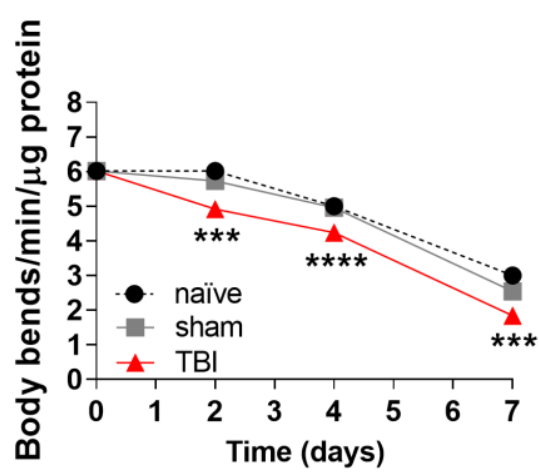

d

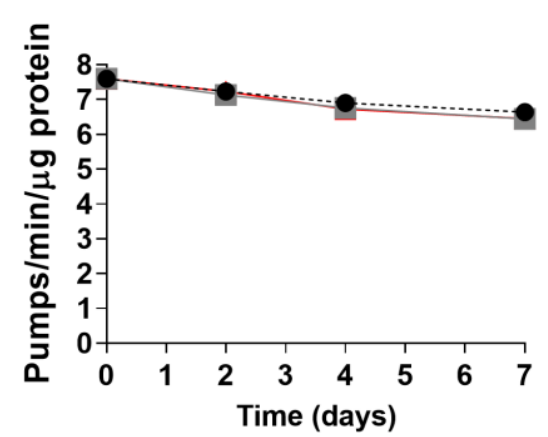

Fig. 1 Brain homogenates from chronic but not acute TBI mice are toxic to $C$. elegans. a Pericontusional tissue homogenates were prepared from the ipsi (TBI ipsi) or contralateral (TBI contra) brain areas from TBI mice $24 \mathrm{~h}, 72 \mathrm{~h}, 3$ months and 12 months post-injury. Brain homogenates from naïve and sham mice were used as controls. b Effects of the different brain homogenates on nematode locomotor activity 7 days after treatment. Data are mean + SEM of three independent experiments using brain homogenates from three different mice/group (50 worms/group). $* * * * \mathrm{p}<0.0001$ vs naïve, ${ }^{\circ \circ} \mathrm{p}<0.001$ and ${ }^{\circ 00} \mathrm{p}<0.0001$, oneway ANOVA and Bonferroni's post hoc test. Time-course of the effect on $\mathbf{c}$ locomotor and $\mathbf{d}$ pharyngeal activity of homogenates from 12-month TBI, sham or naïve mice (30 $\mu \mathrm{g}$ protein $/ 100$ worms $/ 100 \mu \mathrm{L}$ ). Data are the mean \pm SEM of three independent experiments with homogenates from two different mice/group (60 worms/group). ***p $<0.001$ and $* * * * \mathrm{p}<0.0001$ vs sham at the corresponding time-point, one-way ANOVA and Bonferroni's post hoc test 


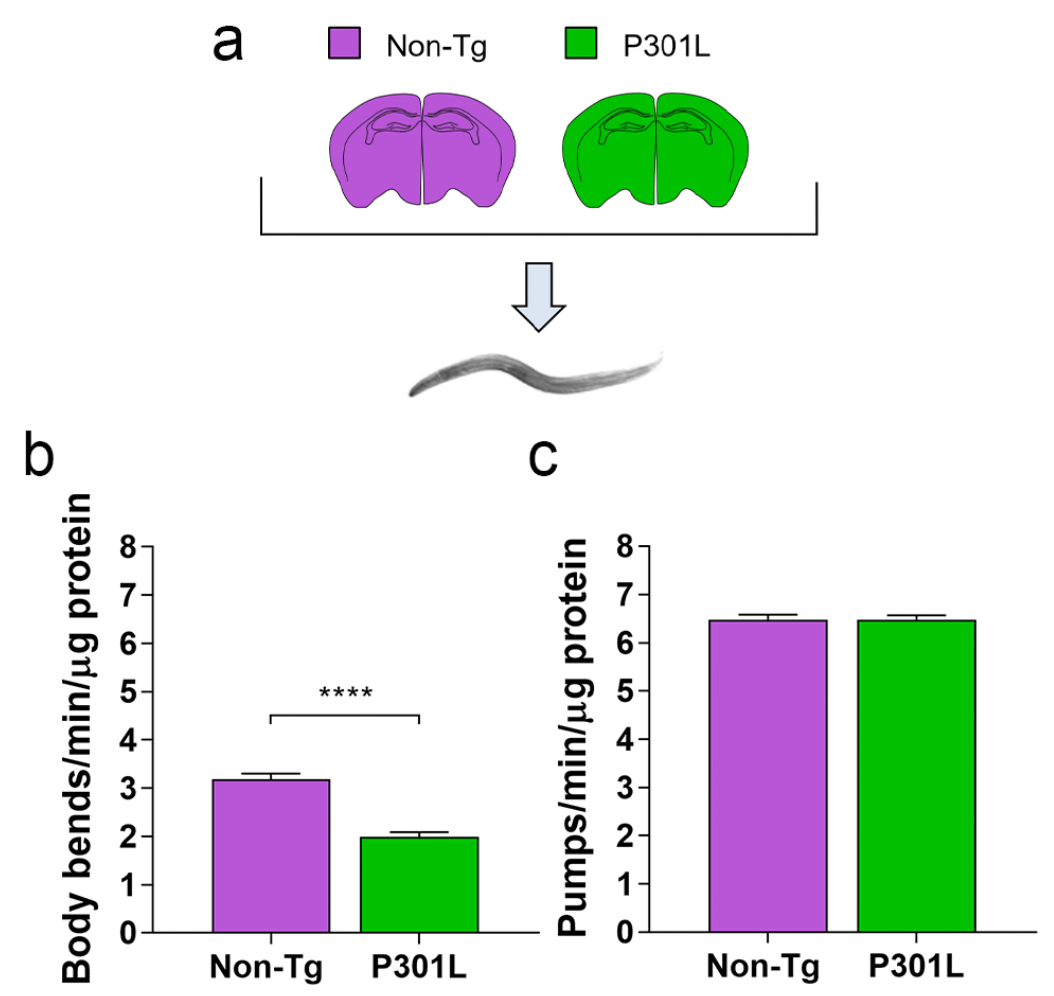

Fig. 2 Brain homogenates from transgenic P301L mice are toxic to $C$. elegans. a Brains from Non-Tg or P301L mice were homogenized in $10 \mathrm{mM} \mathrm{PBS}, \mathrm{pH} 7.4$, and given to worms (30 $\mu \mathrm{g}$ protein/100 worms $/ 100 \mu \mathrm{L}$ ). b Locomotor activity and (c) pharyngeal function of nematodes were rated 7 days after treatment. Data are the mean + SEM of three independent experiments with homogenates from three different mice (70 worms/group). **** $\mathrm{p}<0.0001$ vs Non-Tg, Student's t-test 

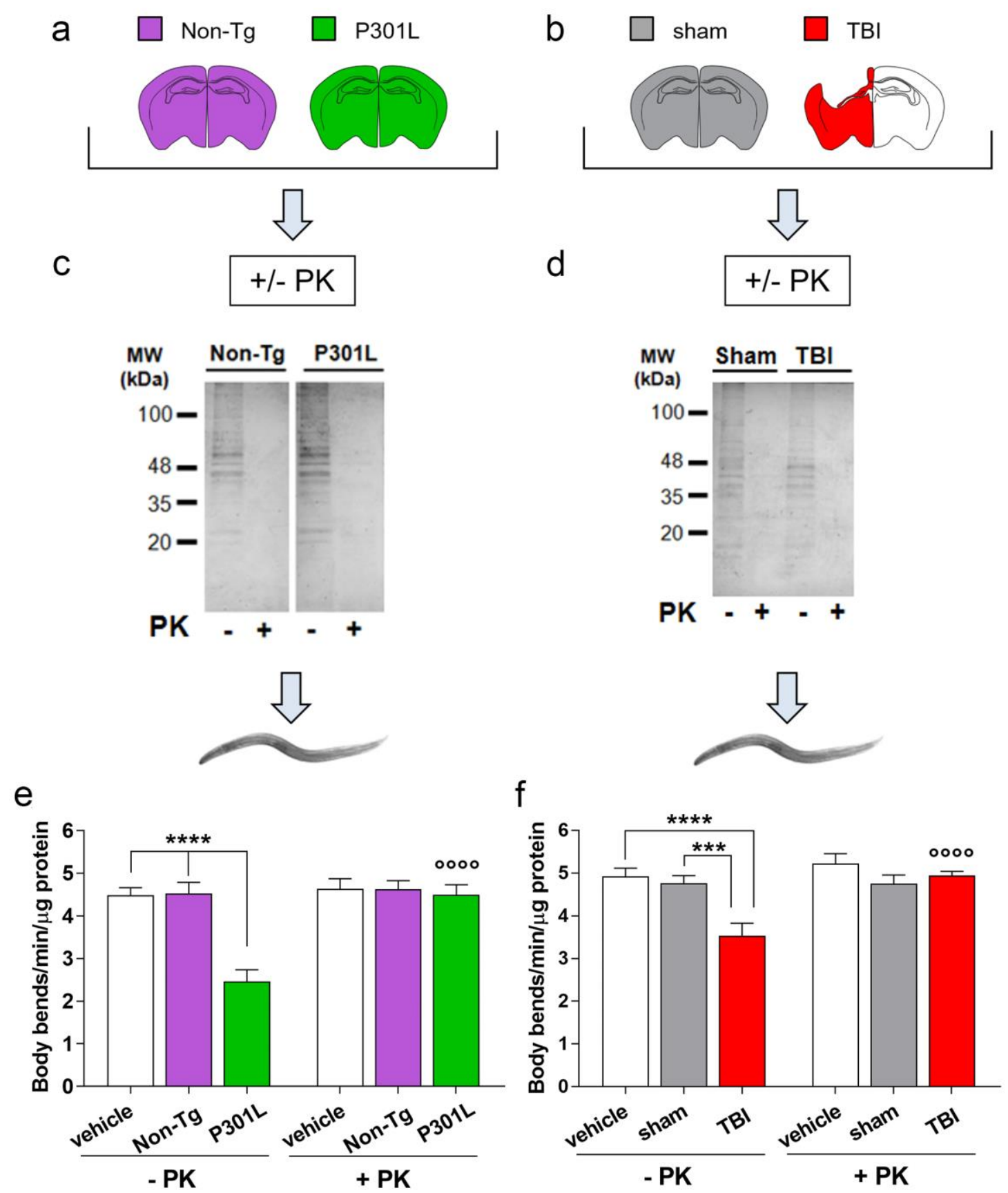

Fig. 3 P301L and TBI brain homogenate toxicities are abolished by pretreatment with proteinase-K. Tissue homogenates ( $30 \mu \mathrm{g}$ proteins) from a Non-Tg, P301L, b 12 months TBI and sham mice, were incubated for $1 \mathrm{~h}$ at $37^{\circ} \mathrm{C}$ with $10 \mu \mathrm{g} / \mathrm{mL}$ proteinase-K $(+\mathrm{PK})$ or the same volume of water (-PK). c, d Protein digestion was evaluated by SDS-PAGE analysis and staining with Comassie Blue ( $2 \mu \mathrm{g}$ proteins/lane). e, $\mathbf{f}$ The same samples were given to $C$. elegans $(30 \mu \mathrm{g}$ proteins $/ 100 \mathrm{worms} / 100 \mu \mathrm{l})$ and the locomotor activity was rated 7 days later. Control worms were treated with $100 \mu \mathrm{l}$ of water $\pm 10 \mu \mathrm{g} / \mathrm{mL}$ PK (vehicle). Data are the mean + SEM (50 worms/group). e ****p<0.0001 and ${ }^{\circ 000} \mathrm{p}<0.0001$ vs P301L-PK, by one-way ANOVA and Bonferroni's post hoc test. Interaction 0.0017, two-way ANOVA and Bonferroni's post hoc test. f $* * * \mathrm{p}<0.001$, $* * * * \mathrm{p}<0.0001$ and ${ }^{\circ 0 \circ 0} \mathrm{p}<0.0001$ vs TBI-PK, oneway ANOVA and Bonferroni's post hoc test. Interaction $<0.0001$, by two-way ANOVA and Bonferroni's post hoc test 



Fig. 4 Anti-tau antibodies abolish P301L and TBI brain homogenate toxicities. Tissue homogenates (30 $\mu \mathrm{g}$ proteins) from a Non-Tg, P301L, b 12 months TBI and sham mice, were incubated for $30 \mathrm{~min}$ at room temperature with $10 \mathrm{ng} / \mu \mathrm{L}$ monoclonal anti-tau T46 antibody (+T46) or the same volume of water (-T46) or $5 \mathrm{ng} / \mu \mathrm{L}$ monoclonal anti-tau SP70 antibody $(+$ SP70) or the same volume of water (-SP70). The homogenates $(30 \mu \mathrm{g}$ proteins $/ 100$ worms $/ 100 \mu \mathrm{L}$ ) were then given to worms and locomotor activity was rated seven days later. Data are mean + SEM (50 worms/group). $\mathbf{c}$ and $\mathbf{d} * * * * \mathrm{p}<0.0001$ and ${ }^{\circ 000} \mathrm{p}<0.0001 \mathrm{vs}$ P301L-T46 or P301L-SP70, Interaction $<0.0001$, $\mathbf{e}^{* * * *} \mathrm{p}<0.0001$ and ${ }^{\circ 000} \mathrm{p}<0.0001$ vs TBIT46, Interaction $=0.0008$, according to two-way ANOVA and Bonferroni's post hoc test 
a



C

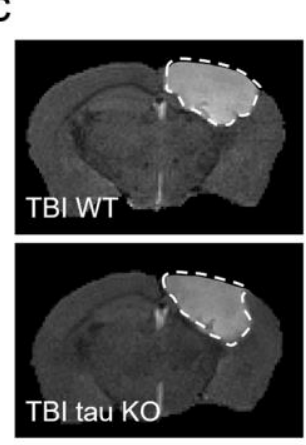

b

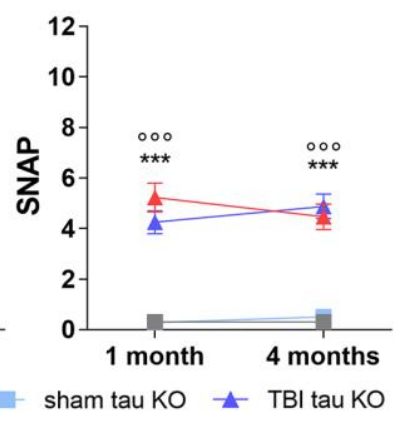

d

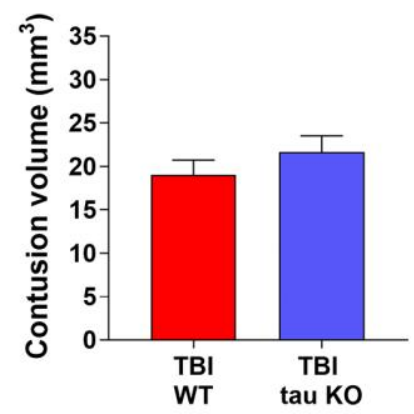

e

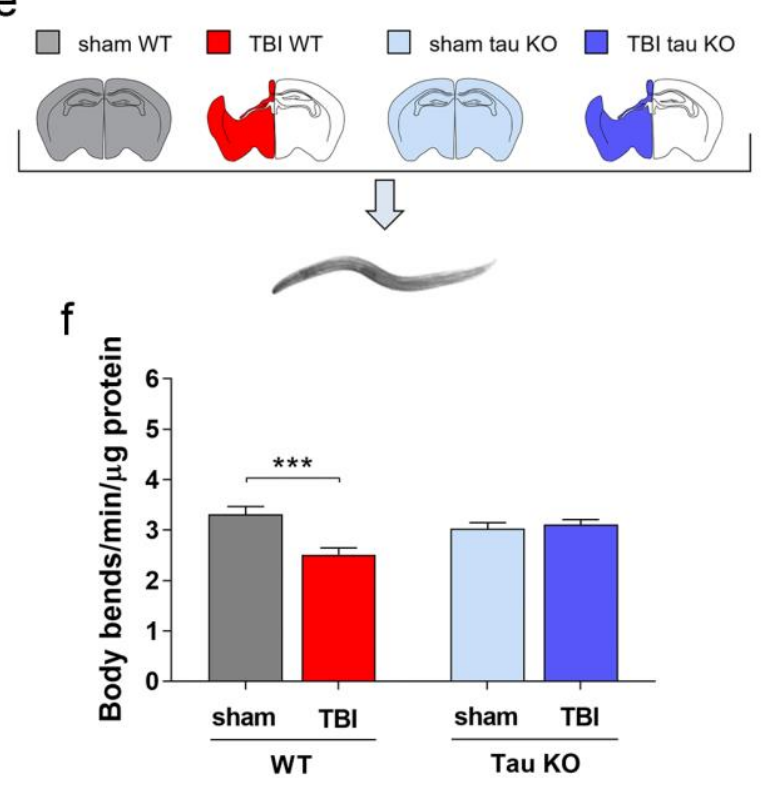

Fig. 5 Brain homogenates from TBI tau knock-out mice are not toxic to $C$. elegans. Sensorimotor function of WT and tau knock-out (tau KO) mice was assessed by a neuroscore and b SNAP tests at 1 and 4 months after severe TBI or sham injury. Data are mean \pm SEM, two way-ANOVA followed by Tukey's post hoc. $* * * \mathrm{p}<0.001 \mathrm{vs}$ sham WT and ${ }^{\circ \circ 0} \mathrm{p}<0.001$ vs sham tau KO. c, d T2w-MRI images were used to evaluate contusion volume in TBI mice 4 months post-TBI. Data are mean + SEM, upaired t-test. e TBI homogenates of WT (TBI WT) or tau KO (TBI tau KO), sham WT or sham tau KO mice sacrificed 4 months post injury, were given to worms $(30 \mu \mathrm{g}$ protein/100 worms $/ 100 \mu \mathrm{L})$. f The locomotor activity of nematodes was scored seven days later. Data are mean + SEM of data from three independent experiments with homogenates from three different mice (30 worms/group). *** $\mathrm{p}<0.001 \mathrm{vs}$ sham, one-way ANOVA and Bonferroni's post hoc test 
a

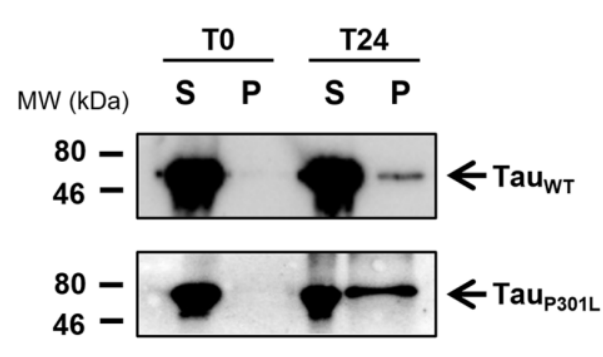

b

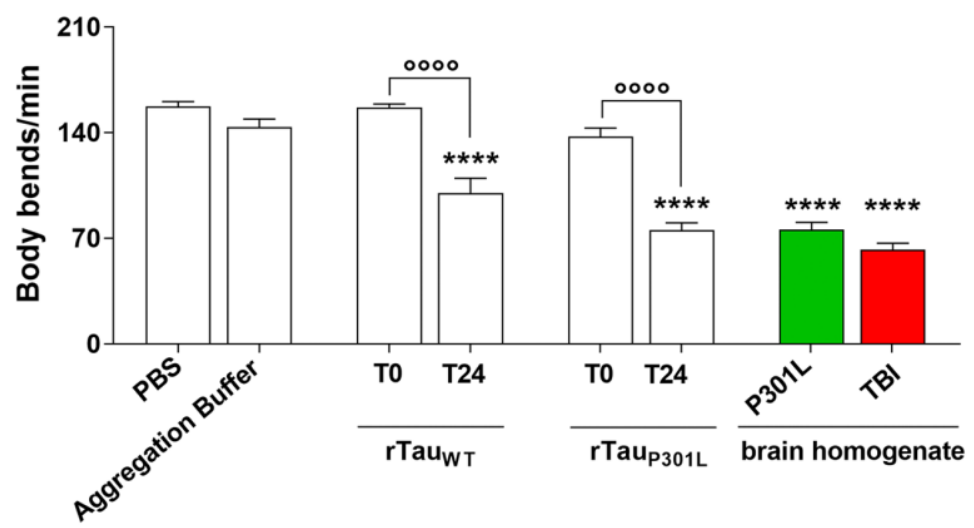

Fig. 6 Aggregated recombinant tau is toxic to $C$. elegans. a A detergent insolubility test was done on TauWT and TauP301L immediately after addition of the co-aggregant heparin (T0) or after $24 \mathrm{~h}$ of incubation at $37^{\circ} \mathrm{C}$ under shaking (T24). The supernatant (S) and pellet (P) were analyzed on $10 \%$ SDS-PAGE followed by Western blotting using the anti-total tau DAKO antibody. b An aliquot of the same proteins was diluted in $10 \mathrm{mM}$ PBS, pH 7.4, and given to worms at the final concentration of $2 \mu \mathrm{g}$ tau/100 worms $/ 100 \mu \mathrm{L}$. C. elegans were treated in the same experimental conditions with $10 \mathrm{mM} \mathrm{PBS,} \mathrm{pH} 7.4$ (PBS) or co-aggregants diluted in $10 \mathrm{mM}$ PBS, pH 7.4 (Aggregation buffer) as negative controls. Locomotor activity was rated 7 days after treatment. The effects of brain homogenates from P301L and 12 month TBI mice respectively (Figures $2 b$ and $1 b$ ), are shown for comparison. Data are mean + SEM (50 worms/group). **** $\mathrm{p}<0.0001$ vs PBS and ${ }^{0000} \mathrm{p}<0.0001$, one-way ANOVA and Bonferroni's post hoc test 
a

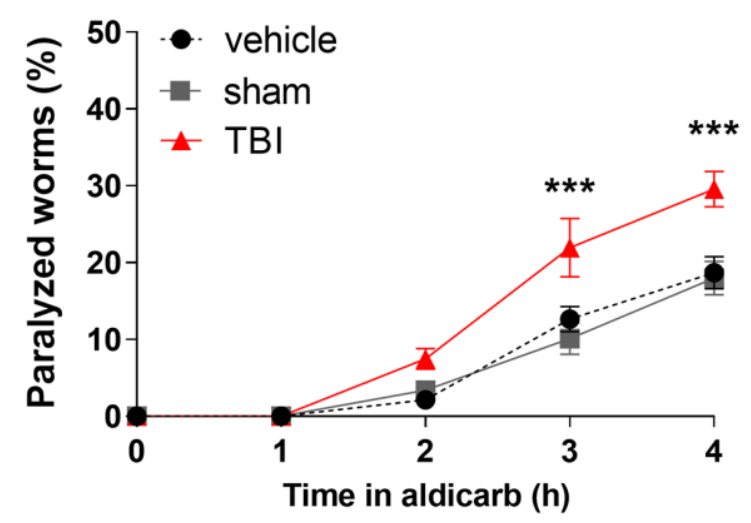

C

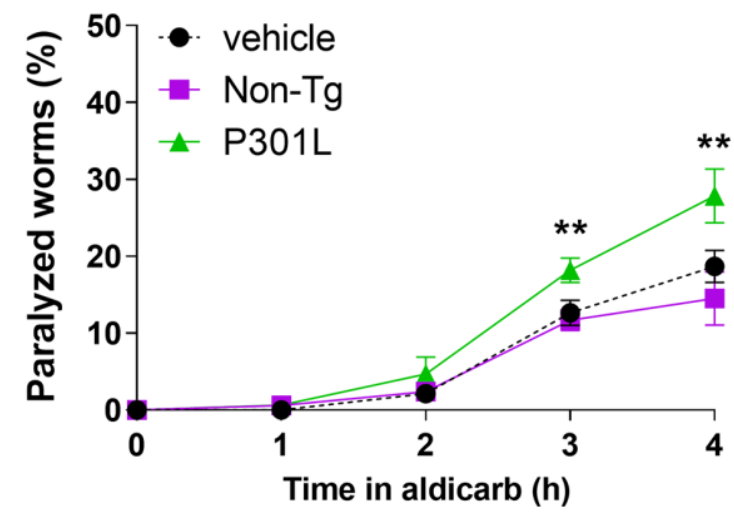

b

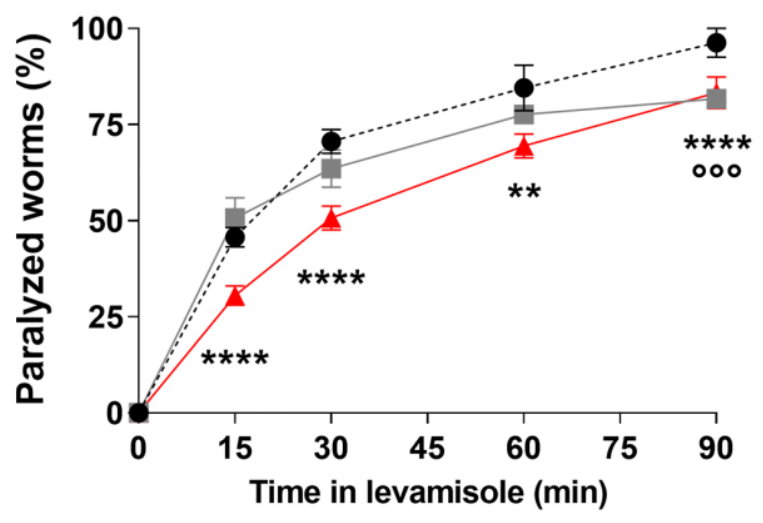

d

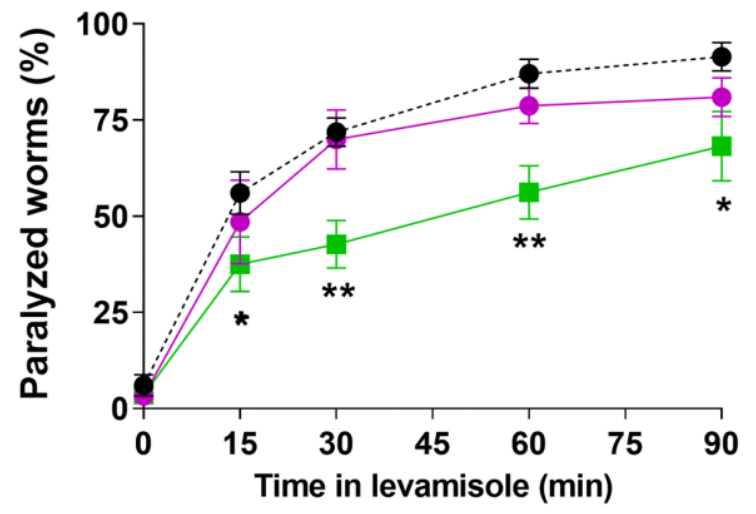

Fig. 7 TBI and P301L brain homogenates induce pre- and post-synaptic defects. The sensitivity of worms to $0.5 \mathrm{mM}$ aldicarb and $1 \mathrm{mM}$ levamisole was evaluated 4 days after treatment with $10 \mathrm{mM}$ PBS, pH 7.4 (vehicle) and brain homogenates (30 $\mu \mathrm{g}$ protein/100 worms $/ 100 \mu \mathrm{L}$ ) from a, b 12 months post-TBI (TBI) and sham-injured (sham) mice or c, d Non-Tg and P301L mice. Data are mean \pm SEM of percentages of paralyzed worms at different times after treatment with levamisole or aldicarb (100 worms/group). $* \mathrm{p}<0.05$, $* * \mathrm{p}<0.001$, and $* * * \mathrm{p}<0.001$ vs Non-Tg or sham at the corresponding times according to oneway ANOVA and Bonferroni's post hoc test 


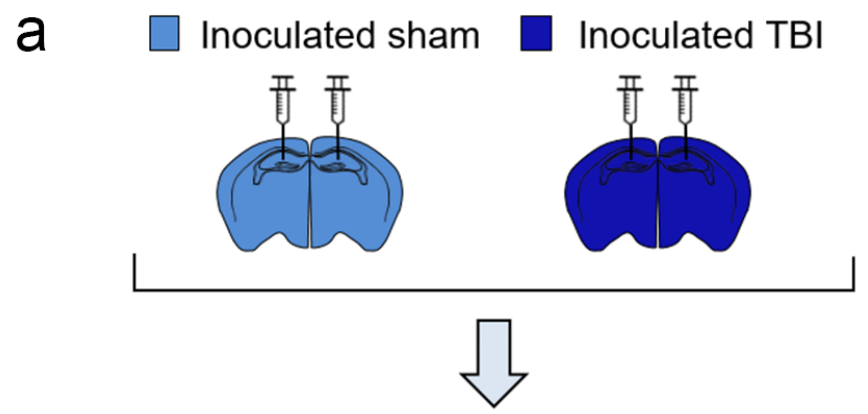

17 months post inoculation

b

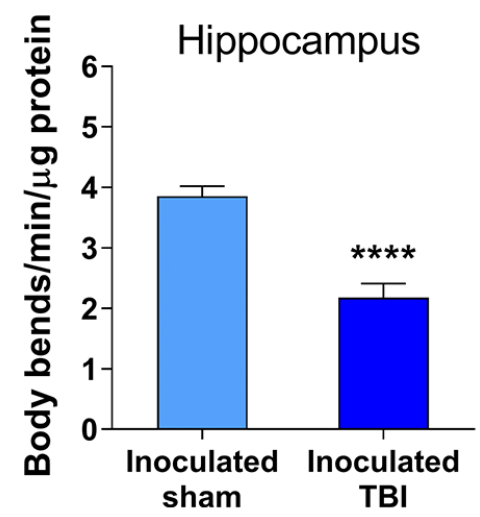

C

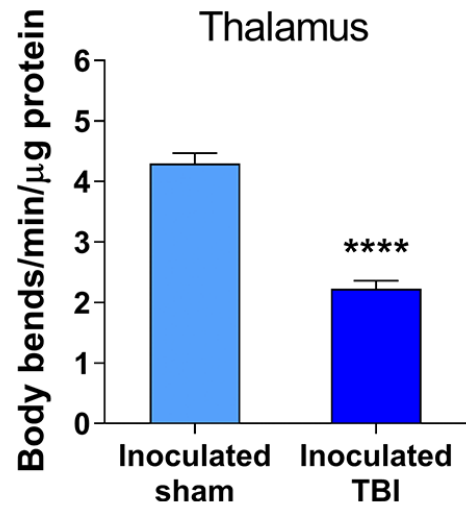

Fig. 8 Brain homogenates from mice inoculated with contused brain tissue are toxic to C. elegans. a Homogenates of hippocampus or thalamus from mice inoculated with 12 months post-TBI (Inoculated TBI) or sham-injured (Inoculated sham) mice were given to $C$. elegans $(30 \mu \mathrm{g}$ protein $/ 100$ worms $/ 100 \mu \mathrm{L}$ ). b, $\mathbf{c}$ Locomotor activity was rated 7 days after treatment. Data are mean + SEM from two independent experiments conducted with homogenates from three different mice (50 worms/group). $* * * * \mathrm{p}<0.0001 \mathrm{vs}$ inoculated sham, according to one-way ANOVA and Bonferroni's post hoc test 
bioRxiv preprint doi: https://doi.org/10.1101/2020.06.18.159301; this version posted June 20, 2020. The copyright holder for this preprint (which was not certified by peer review) is the author/funder. All rights reserved. No reuse allowed without permission. 


\section{SUPPLEMENTARY MATERIAL}

\section{Role of misfolded tau in the onset and progression of brain toxicity after trauma}

Elisa R. Zanier ${ }^{*}$, Maria Monica Barzago ${ }^{2}$, Gloria Vegliante $^{1}$, Margherita Romeo ${ }^{2}$, Ilaria Bertani $^{1}$, Carmina Natale ${ }^{1}$, Luca Colnaghi ${ }^{1}$, Laura Colombo ${ }^{2,}$ Luca Russo $^{2}$, Edoardo Micotti ${ }^{1}$, Luana Fioriti $^{1}$, Roberto Chiesa ${ }^{1 *}$, Luisa Diomede ${ }^{2 *}$

${ }^{1}$ Department of Neuroscience and ${ }^{2}$ Department of Molecular Biochemistry and Pharmacology, Istituto di Ricerche Farmacologiche Mario Negri IRCCS, Milan, Italy.

$\underline{\text { Running title: }}$ TBI generated tau is toxic to C. elegans

*Correspondence to:

Luisa Diomede

Department of Molecular Biochemistry and Pharmacology, Istituto di Ricerche

Farmacologiche Mario Negri IRCCS, Via Mario Negri 2, 20156 Milan, Italy.

E-mail: luisa.diomede@marionegri.it

*Correspondence may also be addressed to:

Elisa R. Zanier, E-mail: elisa.zanier@marionegri.it

Roberto Chiesa, E-mail: roberto.chiesa@marionegri.it 
a

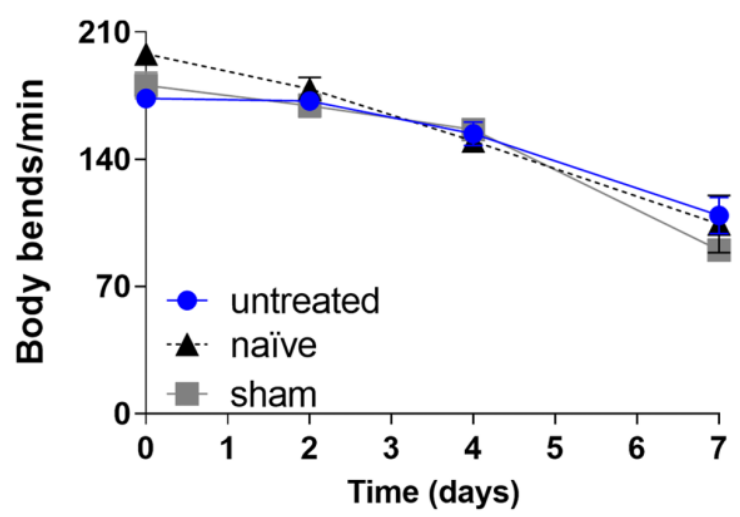

b

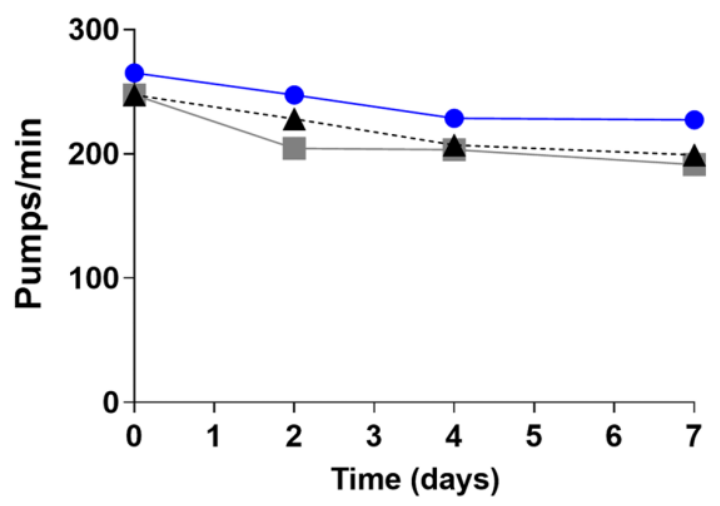

Supplementary Fig. 1 Sham brain homogenates did not modify the physiological agedependent decline of the locomotor and pharyngeal activity of worms. N2 worms (100 worms $/ 100 \mu \mathrm{L}$ ) were treated with $30 \mu \mathrm{g}$ protein of brain homogenate from naïve or sham injured mice (sham). Untreated worms were used as control. The locomotor activity a and pharyngeal function $\mathbf{b}$ of nematodes were rated from day 1 to day 7 after treatment. Data are mean \pm SEM of data from three independent experiments with homogenates from two different mice (30 worms/group) 


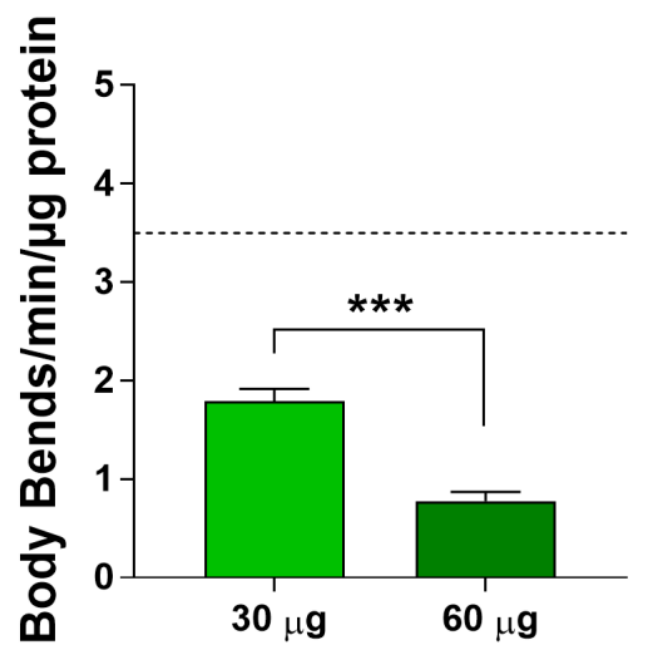

Supplementary Fig. 2 Dose-dependent effect of P301L brain homogenate on C. elegans locomotion. $\mathrm{N} 2$ worms $(100$ worms $/ 100 \mu \mathrm{L})$ were treated with 30 or $60 \mu \mathrm{g}$ protein of brain homogenate from Non-Tg (dotted line) or P301L transgenic mice (green column) and their locomotor activity was rated 7 days later. Data are mean $\pm \mathrm{SE}$ (30 worms/group). ***p<0.001 according to one-way ANOVA and Bonferroni's post hoc test 
a

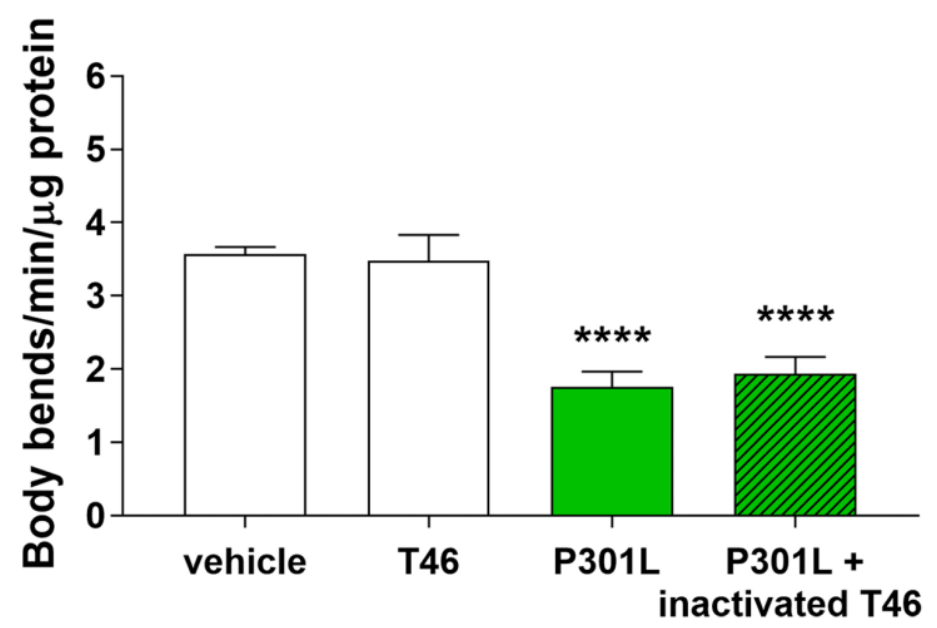

b

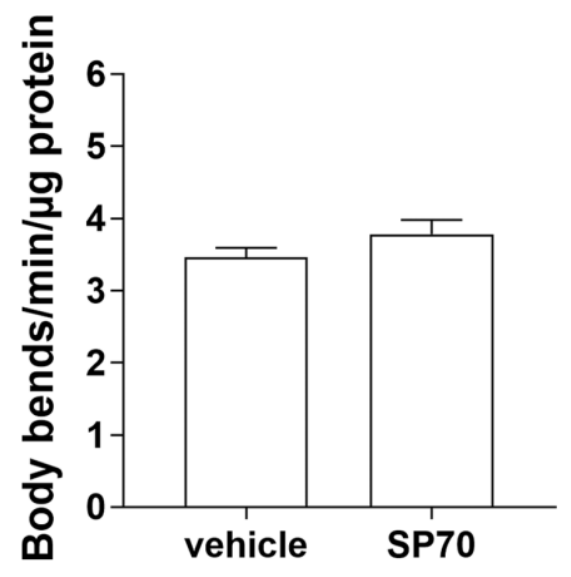

Supplementary Fig. 3 The anti-tau antibodies have no effect on $C$. elegans motility and heat inactivation abolished the antibody's ability to rescue the $P 301 \mathrm{~L}$ brain homogenate-induced locomotor defect. a The brain homogenate from P301L mice was administered to worms $(30 \mu \mathrm{g}$ proteins/100 worms/100 $\mu \mathrm{l})$ before (P301L) or after $30 \mathrm{~min}$ pre-incubation for at room temperature with the monoclonal anti-tau T46 antibody (10 $\mathrm{ng} / \mu \mathrm{L})$ previously inactivated by incubation at $100^{\circ} \mathrm{C}$ for $10 \mathrm{~min}(\mathrm{P} 301 \mathrm{~L}+$ inactivated $\mathrm{T} 46)$. The effect of antibody alone was also examined by treating worms (100 worms/100 $\mu \mathrm{L})$ in the same experimental conditions with a $10 \mathrm{ng} / \mu \mathrm{L}$ monoclonal anti-tau T46 antibody (T46) or b $5 \mathrm{ng} / \mu \mathrm{L}$ monoclonal anti-tau SP70 antibody (SP70). Control worms were treated with 10 mM PBS, pH 7.4 (vehicle). The locomotor activity of nematodes was rated seven days after the treatment. Data are mean \pm SE. $* * * * p<0.0001 v s$. vehicle, one-way ANOVA and Bonferroni's post hoc test 
a

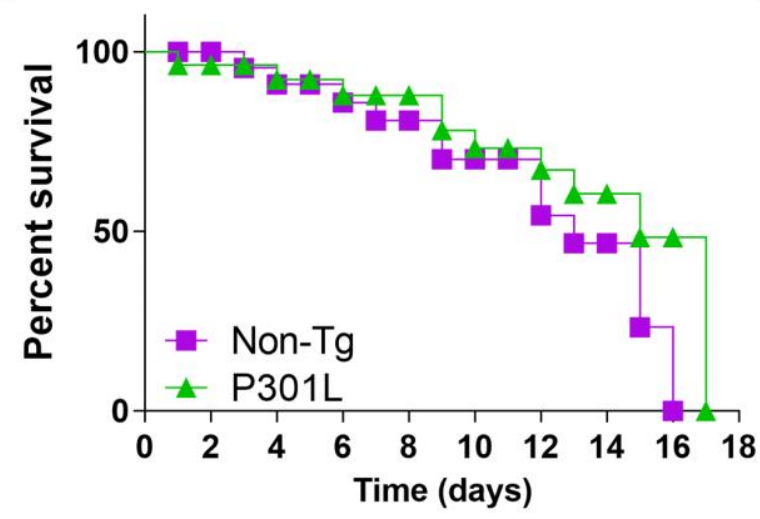

b

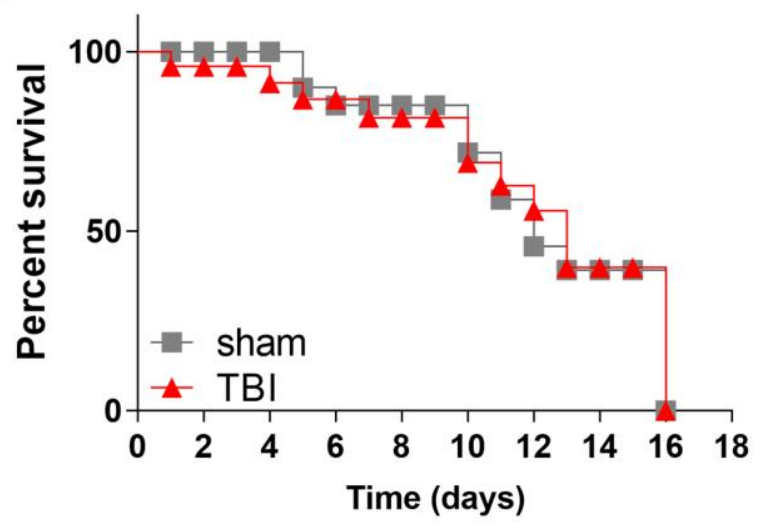

\begin{tabular}{|l|c|}
\hline TREATMENT & MEDIAN SURVIVAL (days) \\
\hline Non-Tg & 13 \\
\hline P301L & 14 \\
\hline sham & 12 \\
\hline TBI & 13 \\
\hline
\end{tabular}

Supplementary Fig. 4 TBI and P301L brain homogenates do not affect $C$. elegans lifespan. a Brains from Non-Tg and P301L mice or b pericontusional tissue homogenates from the ipsilateral brain area of 12 months post-TBI mice (TBI) and brain homogenates from sham mice (sham), were homogenized in $10 \mathrm{mM}$ PBS, $\mathrm{pH} 7.4$, and given to worms (30 $\mu \mathrm{g}$ protein $/ 100$ worms $/ 100 \mu \mathrm{L}$ ). The number of live worms was counted daily and plotted on Kaplan Meier curves. Day 0 of the curve corresponds to the day of brain homogenate administration (L4 larval stage of worms). Data are from two independent experiments (30 worms/group). The percentage of live worms seven days after treatment and the median survival were calculated. $\mathrm{P}>0.05$ according to Log-rank and Gehan-Breslow-Wilcoxon tests 